\title{
The local business analysis service for service-oriented government: Seoul Metropolitan Government Case
}

\author{
June-Suh Cho \\ KwangJong Ahn \\ Hankuk University of Foreign Studies \\ Seoul, Korea
}

\section{Keywords}

big data, data analysis, e-Government, service-oriented

\begin{abstract}
The transition into a service-oriented government is the focal point of the Seoul Metropolitan Government (SMG) administrative transformation. This transformation must be conducted according to the specific needs of each local municipality. SMG provides a customized service for individual citizens and support job creation by opening and sharing public information and offering the advanced service to help their local business which is called 'Golmoksangkwon Analysis Service'. This service is using big data analysis and service-oriented government in SMG. This paper discusses the efforts of SMG to provide information service which is based on big data analysis for local businesses. Information providing units for commercial and sector analysis were constructed from the various viewpoints by establishing a local business area including the existing administrative districts. SMG expects to contribute to improving the competitiveness and selfsufficiency of self-employed people by supporting the policy macro perspective of self-employed people by analyzing the factors affecting the business environment of the local business through big data analysis.
\end{abstract}

Corresponding author: June-Suh Cho

Email addresses for the corresponding author: jscho@hufs.ac.kr

First submission received: $20^{\text {th }}$ February 2019

Revised submission received: $27^{\text {th }}$ March 2019

Accepted: $20^{\text {th }}$ April 2019

\section{Acknowledgement}

This study was supported by Hankuk University of Foreign Studies Research Fund of 2019.

\section{Introduction}

E-government has achieved significant improvements through the deployment of many innovative applications. (Gronlund \& Horan, 2005; Lee, Tang, \& Trimi, 2005) Citizens use government web sites as central points of access to government information and services across different agencies via Internet or Mobile access. Transformation of government processes, transactions, and policy making and implementation that are efficiently carried out through ICTs. Through ICT, new forms of collaboration and inter-organizational public service networks become feasible, making it possible to carry out the public sector's tasks more efficiently and effectively. As a leading country of e-Government services, Korea's e-Government is transforming into citizen friendly services. In particular, Seoul Metropolitan Government (SMG) as a leader in Korea, tries to provide customized services for individual citizens and support job creation by opening and sharing public information and offer the advanced service to help their local business.

Governments of leading ICT countries have initiated big data application projects to enhance operational efficiency, transparency, citizen's well-being and engagement in public affairs, economic growth, and national security. (Kim, Trimi, \& Chung, 2014) Also, governments expect big data to enhance their ability to serve their citizens and address major national challenges involving the economy, healthcare, job creation, natural disasters, and terrorism. Among them, start-up and job creation are one of the major issues in SMG. SMG introduced a local business analysis service, which is call 'GolmokSangkwon Analysis Service', based on big data analysis as a way to support and expand it. With 
the development of the fourth industrial revolution, e-government is evolving service-based egovernment using big data analysis.

SMG provides a customized service for individual citizens and support job creation by opening and sharing public information and offering the advanced service to help their local business with 'Golmoksangkwon Analysis Service'. SMG introduced a local business analysis service, which is based on big data as a way to support and expand it. The objective of this service is to provide information service which is based on data analysis for local business. This service is to overcome the difficulties of the operation of the pre-founder and self-employed and to provide practical support for their business.

In this paper, we discuss the 'Golmoksangkwon Analysis Service', which is a local business analysis service using big data analysis and service-oriented government with Seoul Metropolitan Government (SMG) case. Innovative service through ICT should contribute to change citizen's life, local community, and government. The big data analytics on local business community and its benefits are discussed along with the impact on the effective e-government.

\section{Theoretical Background \\ Service-oriented Government}

The emergence of e-commerce and $\mathrm{Y} 2 \mathrm{~K}$ advanced e-government, as governments began to adopt the changes taking place in the private sector. E-government is defined in various ways. (Relyea \& Hogue, 2004; Seifert \& Relyea, 2004) Some definitions of e-government are limited as a unit of the government, while others are very broadly defined, with e-governance integrated throughout the government. World Bank defines e-government as "the use by government agencies of information technologies (such as Wide Area Networks, the Internet, and mobile computing) that have the ability to transform relations with citizens, businesses, and other arms of government." (Jeong \& Kim, 2003; Kushchu \& Kuscu, 2003; Trimi, \& Sheng, 2008) These technologies can serve a variety of different ends: better delivery of government services to citizens, improved interactions with business and industry, citizen empowerment through access to information, or more efficient government management. (Gronlund \& Horan, 2005; Reddick, 2005; Tian \& Tianfield, 2003) The resulting benefits can be less corruption, increased transparency, greater convenience, revenue growth, and cost reductions." (Definition of E-government, World Bank)

E-government is a transformation of government processes, transactions, and policy making and implementation that are efficiently carried out through information and communication technologies to provide better and efficient services to the citizens while reducing waste and corruption and increasing accountability, transparency, and trust. Furthermore, it is about creating a one-to-one relationship with the government in which citizens are empowered to take part in the democratic process and policy making. E-government is increasingly being implemented in all areas of government administration at both the local, regional and national levels, increasing efficiency and transparency and bringing convenience and safety to citizens' lives, and consequently improving the quality of life. (Mulgan, 2000; Northrup \& Thorson, 2003) While it was initially promoted as a means of improving internal management efficiency in public administration, e-government is increasingly considered an important measure for enhancing citizen access to government services and expediting the delivery of services to citizens. (Morris \& Moon, 2005) E-government is used to enhance citizens' access to government as much as government's access to citizens using current network technologies. (Heeks. \& Bailur, 2007; Irani, Love, \& Montazemi, 2006; Premkumar, Ho, \& Chakraborty, 2006; Seifter \& Chung, 2008)

E-government has intrinsic unity of value with service-oriented government, implementing egovernment, strengthening social management and public service is an inevitable requirement for building service-oriented government. The effects of e-government in the service-oriented government building manifested through the interaction between government and citizens, government and enterprises and institutions, and governments themselves. E-government can enhance the concept of government services, promote the transformation of government functions, and improve the efficiency of government operations.

Engaging citizens in public governance has not only an intrinsic value in terms of deepening democracy, but it can also be instrumental in enhancing governments' capacity to deliver quality education services, promote gender equality and empowerment in public administration and society at 
large, deliver health services which can help reduce child mortality, improve maternal health, as well as eradicate disease, and promote a sustainable environment. Implementing effective service and engaging citizens to take a more active role in development and in decisions that affect their lives poses.

The Korean government places citizens at the heart of all public services. It provides individual citizens with public services customized to their characteristics and life cycles. The Korean government also uses new information technology to realize whole new administrative services in the fields of life, disaster management, environment, and security. In terms of the integrated provision of customized services, each government agency selects priority policies and services that are most requested by citizens and provides customized services. The government classifies its services by type of beneficiaries including childbirth, upbringing, the disabled and the elderly, and provides customized services.

To enhance one-stop services for businesses, Korean government will establish an integrated system for small-medium size enterprise support (SME) and manage track records of SME support projects of central and local governments in a systematic manner. Local governments will establish the one-stop permit processing system for businesses and simplify approval processes for start-ups and businesses.

To improving access to services for the information poor, Korean government will improve the service delivery system and accessibility for vulnerable groups to minimize blind spots in public services. Text-to-speech conversion of civil petitions, improving web accessibility of the disabled, providing ICT aids.

The government will also take advantage of the nationwide coverage of postmen networks, thereby enhancing civil affair and welfare services for vulnerable groups in rural areas, such as elderly living alone.

To improve citizen's well-being, engagement in public affairs, economic growth, they are addressed to healthcare, job creation, nature disaster, and so on.

In this paper, we introduce the local business analysis service to support citizen's job creation and business management using big data analysis and provide a service to overcome the difficulties of the operation of local business's owners.

\section{Big Data Analysis in e-Government}

The global spread of the internet and the application of ICTs in government, as well as greater investments in telecommunication infrastructure coupled with capacity-building in human capital can provide formidable opportunities to transform public administration into an instrument of development at the service of its citizens. ICT is a powerful tool for social and economic development. It promotes people's empowerment, participation, access to information, education and networking possibilities for all social groups, particularly older persons, young people, persons with disabilities and indigenous peoples. ICT applications are introduced to upgrade service delivery, including in terms of their greater effectiveness, efficiency, timeliness and quality, for wider access to services, and a more "citizen-centered" approach to services.

It is clear from this statement that ICT in government is a tool, an enabler and not an end in itself. there is a widespread consensus that ICT alone cannot effect change. In order to produce "public value" we must approach the issue of technology from a holistic perspective where changes in one area need to be accompanied by changes in other areas of government operations. Most importantly, there is a strong need to promote among public officials a service-oriented mentality as it exists in the private sector, i.e. to build or upgrade human resources capacity in this particular area. This cannot be achieved if there is not first an attempt to modify the organizational culture of the public sector to embrace change and to become service oriented, cost effective and vigilant about performance and results.

Big data (Agnihotri \& Sharma, 2015) refers to data sets that are so large and complex that traditional data processing tools and technologies cannot cope with. The process of examining such data to uncover hidden patterns in them is referred to as big data analytics. Data is growing at a high speed and its analysis with various mining techniques giving rise to the valuable results in term of best perception for the future. (Bertot \& Choi, 2013) This paper focuses on the impact of big data analysis for the E- 
governance. Getting insight to the results of the predictive analysis can give huge benefits to the Egovernance.

(Agnihotri \& Sharma, 2015) discussed asserts that the public sector doesn't getting that much information from big data as compared to other sectors as public sector doesn't keep track of the analytics of big data compared to others. Irrespective from the amount of data available government can provide better services with the analytics of the data to the citizens this is the thinking of everyone. (Chen, Chiang, \& Storey, 2012) discussed the following areas where web analysis has started and their causes for future and further references are discussed. These areas are campaign advertising, voter-mobilization, policy discussion, donations, and many more other areas. Interesting fact is that most of the work in such fields are done by the government itself and remaining contribution is given by the academicians. Big data is in fact playing a major role for the future actions and for providing best of the services.

There are four main principles that should guide innovation efforts in service delivery as follows:

1. Quality - High quality service delivery may be manifested in - but is not limited to - the availability of government services at times and in ways that are more convenient to the public, speedy processing of applications or claims, reduction in the amount of paperwork and other activities citizens must perform in order to demonstrate compliance of clearly written government regulations.

2. Access - such as the expansion of the coverage or enhancement of quality service delivery to vulnerable groups is critical to inclusive social development.

3. Cost-effectiveness -Utilizing the most economic models for delivering quality services to the citizens and ensuring effective delivery is essential, particularly in times of financial crisis.

4. Citizen-centric - Utilizing mechanisms that have proven to collect feed-back from citizens and that succeed in engaging them in the delivery of services.

Progress in increasing the quality, access, cost-effectiveness and responsiveness of public services has been uneven across the globe. While some countries have been able to successfully reform their public service delivery systems and institutions to meet today's challenges, others have not been able to do so despite several efforts.

In this paper the big data analytics on local business community and its benefits are discussed along with the impact on the effective e-government.

\section{The Local Business Analysis Service using Big Data in SMG}

One of the main issues of SMG is 'Job creation' with local businesses. The objective is to provide information related to the trade through the big data based local business analysis service provided by SMG, to overcome the difficulties of the operation of the pre-founder and self-employed and to provide practical help.

To accomplish these goals, SMG started a service to help small businesses in local area in the city. Local business area, which is called 'Golmoksangkwon', is a range of commercial forces formed along narrow roads near residential areas, not on the street. SMG is defined local business area as follows.

Scope that does not include large distribution facilities.

- A place where housing is concentrated.

- A four-lane highway back street

- Execute wholesale and retail business, restaurant business, and service business.

- Over 50 wholesale and retail, service and service areas.

Korean government removes barriers among government agencies to strengthen sharing and interconnection of information, maximizes work efficiency through digital collaborations, and upgrades the quality of public administration and citizens' lives using big data. Korean government makes better use of various forms of big data in public administration, thereby developing scientific, proactive policies and providing customized services. It establishes a government-wide support system for predictive data analysis and advance identification of changes and risk factors. Korean Government is enhancing the private sector's use of public data, they develop a government-wide public data disclosure roadmap and disclose $12,000(60 \%)$ out of 21,000 types of public data by 2017. In particular, it selects promising 
businesses in 15 strategic fields that face strong demands from the private sector, such as transportation, patent, and employment/labor, and help commercialize their business to create jobs.

As a leading country of e-Government services, Korea's e-Government is transforming into citizen friendly and service-oriented services. In particular, SMG tries to provide customized services for individual citizens and support job creation by opening and sharing public information and offer the advanced service to help their local business. SMG has analyzed the credit card sales and rental quotes for small business owners who want to start business and started 'Golmoksangkwon Analysis Service` which summarized by region. SMG has decided to set the local as a business area, including the locals that do not have large-scale distribution facilities, and analyzing the merchandise based on the card usage data and sales consumption data for the life insurance businesses such as Chinese restaurants and convenience stores On the website(golmok.seoul.go.kr), you can see 'Commercial Traffic Light', which shows business risks based on the commercial growth rate and the average closing time of the business. Also, information in the number of stores, average sales, and floating population of the locals in the local can also be retrieved. Furthermore, even if it does not correspond to 8 areas of local business area, if you set the area you want, you can get the report of the trend of the floating area by the day of week, the time zone.

According to the SMG's analysis of licensing data for lifestyle-related industries in 2016, the survival rate of shops opened 10 years ago was $2.8 \%$ lower than that of $21 \%$ for locals. However, the average sales period was 8.9 years for local commercials, slightly longer than 8.3 years for development commercials.

\section{Service construction background}

This service needs to solve the difficulties of the market and secure the stable operation and activation of the commercial market for the self-employed who are suffering from intensified market competition and competition with large retailers. To do this, we provided detailed information about the commercial area to help the business.

\section{Self-employed market with dense saturation}

There is a growing trend for the number of self-employed businesses, including retired baby boomer generations and young people who are facing job hunting, and competition is fierce. This service protects the existing self-employed and provide reasonable information on the status of the business to entrepreneurs.

\section{Need to stabilize and activate commercial sector}

Due to the high concentration of similar businesses in the market, due to the nature of low street barriers, short-term closure and conversion rates are high. Therefore, it is necessary to respond appropriately to market changes and reduce uncertainty to improve profitability. By analyzing the big data, we anticipate the change of the local merchandise, thereby creating not only the needs of the customers but also the effective demand to activate the market.

\section{Production and provision of relevant information relevant to the local business area}

Consumer behavior changes continuously as economic and social environment changes and market structure changes cause uncertainties. It is necessary to produce and provide relevant information on the supply of commerce, competitive structure, and changes in consumer trends.

\section{Application data}

An analysis was conducted to provide information on the local merchandising units by using 200 billion big data per year. The analytical data set provided analysis and information by supplying 32 kinds of data sets to provide business information.

- The company received 200 billion Korean won annually through alliances with public and private institutions such as shopping malls, stores, consumption patterns, and floating population to build big data related to the trade.

- Based on commercial data, we developed information that can identify business entities such as start-up risk indicators, industry-related indicators, and sales trends. 


\section{‘Golmoksangkwon' Analysis Service}

Our local business analysis service is to select 43 non-living jobs that self-employed people are most active in, based on the big data related to the trade, which SMG owns or is secured in cooperation with external organizations, this service is as follows.

Citizens' service provides analysis of the local business area based on big data for small business owners who want to start business or industry change, and implements it on the map, and provides information on new business start-up risk and regional business area analysis by clicking on the area.

Expert service is a service that helps pre-founders and existing self-employed to effectively consult about business changes, profitability, stability, growth potential, etc.

The policy utilization service supports the start-up department of SMG and the autonomous regions to monitor the impact of the policy support on the business environment of the local business area, thereby shifting the support to self-employed from policy perspective to macro level, it is also used in the process of establishment and enforcement.

Based on this data, 43 large-sized businesses that are self-employed are selected by the Seoul Metropolitan Government and are provided with a variety of information by sector, based on this data.

We provide statistical information on self-employment and analytical functions that can analyze the indicators related to business start-ups in the business areas such as commercial traffic signal.

Big Date base for Business area

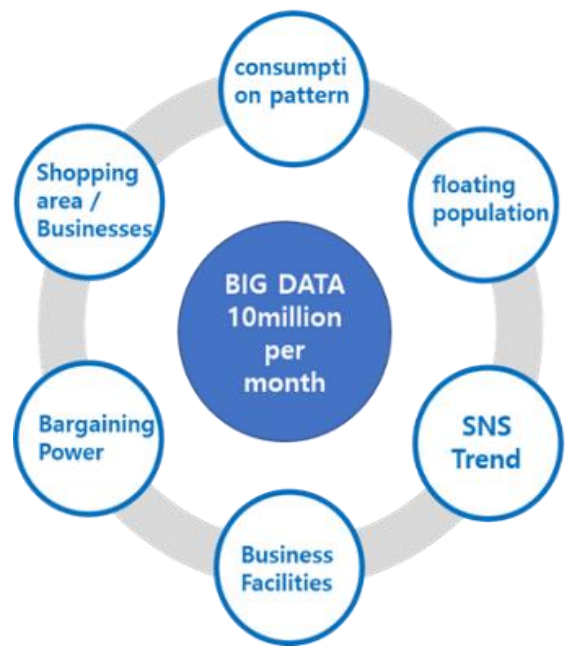

Provide Information for Business area

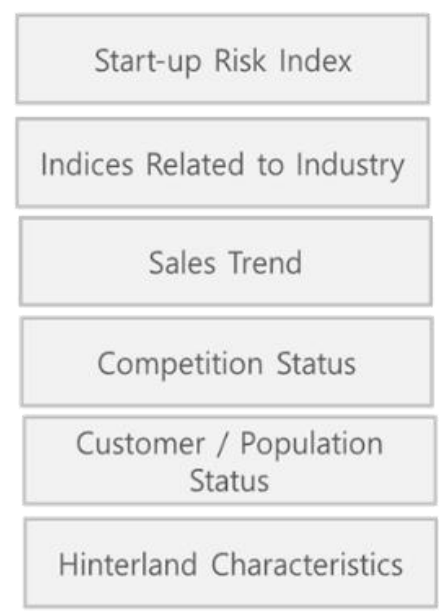

Figure 1. Local Business('Golmoksangkwon') Analysis (SMG, 2017)

We also provide functions to search customized business type, area, and business conditions and search for your business reports. In addition, you can search by simple information on the map, or search quickly by region or business name. If you designate your own store location and industry as a service for existing self-employed users, and you want to freely draw up the merchandise you want to analyze, you can use marketing reports to provide information on the types of customers and consumption characteristics. Trendy themes search by business category theme by region and compare business indexes, compare key indexes among business areas, and view business reports of each business area.

Local business analysis service provides three things. Commercial traffic light service for prefounders, customized commercial search service, and mall marketing service for existing self-employed.

The commercial traffic light service is a service that allows you to check the new business start-up risk level in four steps based on the quarterly business data, so that you can check the start-up risk level, closure rate, and average closing time.

The customized business search service allows you to customize the search for specific trade reports such as the number of stores in the locals of interest, the average sales per store, the daily average floating population, the start-up survival rate, and the over-crowing index among 1008 locals. 
My-store marketing service can analyze the trend of the floating population by sex, age, day and time, and the number of major hospitality facilities and the number of apartment units in the area if the desired business area is set on the map, even if it is not included in 1008 business areas. It also provides a mailing service for analysis reports so that you can regularly check changes in the trade.

Figure 2 shows the Start-up risk index, which represent New start-up risk, closing rate, closing rate compared to practice for three years, Average closing period, and Store growth rate.

New start-up risk is an index made by combining the risk with the closure rate and the 3-year survival rate at the time of new entrepreneurship based on 43 life-friendly industries in the administrative district.

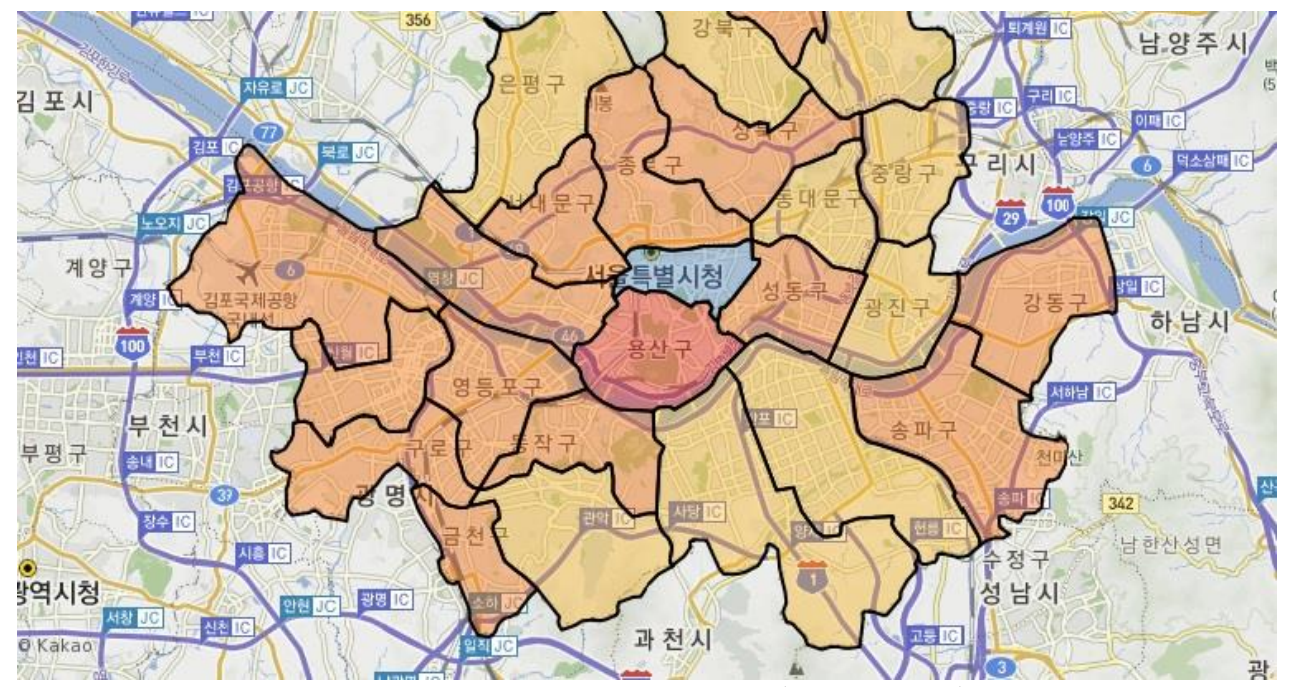

Figure 2. Start-up risk index (SMG, 2017)

Using the two - year standardization interval, we implemented four relativity indices.

The caution is that the risk of new start-ups is relatively low, but you need to be careful when starting up. Suspicion is the area where the risk of new start-up is relatively high, and there is a risk in start-up, and it is an area where decision-making must be careful.

Risks are areas where the risk of new entrants is relatively high and there is a significant risk of entrepreneurship.

High risk is the area where there is a high risk of start-up because the risk of new start-up is relatively high.

The closing rate is calculated by dividing the number of closed stores by the total number of stores based on the data of the store.

Closing Rate: (Number of closed shops / Total number of stores) * 100

Total number of stores:

Total number of stores currently open + Number of stores closed during the period

The closing rate compared to practice for three years is calculated by dividing the number of closed stores by the total number of stores based on the data of the store.

Closing Rate compared to practice for three years:

(Number of closed shops / Total number of stores) * 100

The average closing period is calculated by calculating and averaging the number of months of sales based on the opening and closing days of the store for 10 years.

The store growth rate is the information obtained by comparing the number of stores in the current period with the same period in the previous year.

Store growth rate: 
(Number of stores in previous year - Number of stores in current year) / Number of stores in previous year * 100

In order to calculate risk index, this service use Geographically Weight Regressions.

$$
\begin{gathered}
Y_{i}=\beta_{o i}+\sum_{k=1}^{m} \beta_{k i} X_{k i}+\epsilon_{i} \\
Y_{i}: i \text { Local Dependent Variables } \\
X_{k i}: \text { kth descriptive variable for } i
\end{gathered}
$$

The meaning of the GWR risk index model is the relationship between the closing rate and the closing explanatory variable of the commercial company varies depending on the commercial sector. Also, the different relationships of each business area reflect the risk of each business area. The different coefficients for each model are used as a risk index by assigning weights according to the validity of the variables.

\subsection{Local Business Support Structure}

In SMG, we are monitoring potential merchants and alleged self-employed businessmen, as well as information related to the trade.

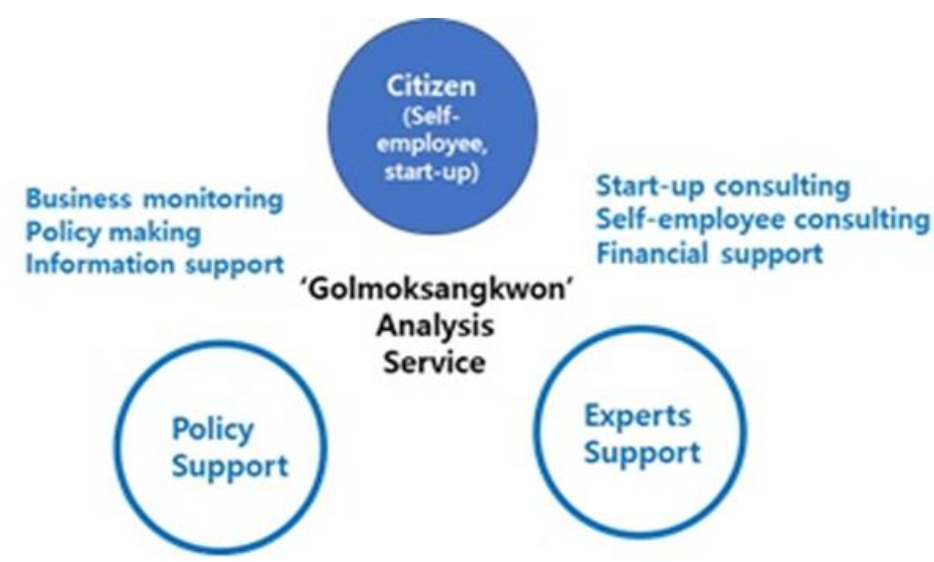

Figure 3. Local Business Support Structure (SMG, 2017)

Figure 3 shows the structure of local business support. Commercial entrepreneurs that are established by ordinary people tend to start up in local business areas based on residential areas. Also, in the case of a business area, citizens who do not have experience in starting a business are in a difficult situation to know the area where a business area is formed. More than 200 professional consultants from the Seoul Metropolitan Small Business Management Support Center are using them to support selfemployment and start-up consulting through expert local trade analysis services. SMG is analyzing the difficulties of self-employed people in the local area through Big Data and making efforts to reflect them in the policy to provide practical help.

To help professional consultants conduct comprehensive and scientific consulting such as business transformation, sales growth, marketing, etc., in consideration of changes in the self-employment environment through analysis of big data.

\subsection{Performance and Implications of Analysis Results}

In this service, information providing units for commercial and sector analysis were constructed from the various viewpoints by establishing a local business area including the existing administrative districts. Through our local business analysis service, we provide information on sales patterns of each business type, season, and high commercial districts, information on business start-ups, and information on 43 types of daily life-related industries, helping to reduce start-up failure and increase self-sufficiency of self-employed people. 
We will use the big data to provide high-quality merchandise information that is essential for the self-employed businessmen in the local area, thereby contributing to the creation and stabilization of jobs by lowering the risk of new entrepreneurs or industries.

\section{Concluding Remarks}

The role of ICTs has dramatically changed over the past decade. Governments are attempting to revitalize their public administration, make it more proactive, more efficient, more accountable, more service-oriented and closer to the people. To accomplish this transformation, governments are introducing innovations in their organizational structure, practices, capacities, and how they mobilize, deploy and utilize the human, material, information, technological and financial resources for service delivery to remote, disadvantaged and challenged people.

The Seoul Metropolitan Government (SMG) has started 'Golmoksangkwon Analysis Service', which analyzes and provides local merchandise information based on Big Data for small and midsize businesses established in overcrowded local market.

Anyone can use this service free of charge through the homepage of SMG. You can freely use menus such as trade statistics, customized commercial search, and mall marketing by accessing 'Golmoksangkwon Analysis Service' without joining a separate member.

This service provides preliminary founders with information on risk and overexposure index of five new traffic lights and various business analysis information to help rational and prudent investment, it is expected to provide an opportunity to increase sales.

Unlike the service of other institutions or private sector, the analysis service of street commerce in SMG provides risk information for start-up. As a result, it is expected that the existing self-employed will be provided with opportunities to improve the business environment and increase sales, and to induce reasonable investment decisions for prospective start-ups.

SMG expects to contribute to improving the competitiveness and self-sufficiency of self-employed people by supporting the policy macro perspective of self-employed people by analyzing the factors affecting the business environment of the local business through big data analysis.

In the future works, we will strengthen data visualization research so that small businesses can intuitively understand and use necessary data, and jointly develop indicators such as 'consumption estimation' and 'sales estimation' to calculate overcrowding index for each trade and provide actual information to preliminary founders and small business owners.

Although, this service needs more efforts to accomplish higher satisfaction against citizen and local government, this service can be expanded into other local governments in Korea as well as other countries as a service-oriented model.

\section{References}

Agnihotri, N. \& Sharma, A. (2015). Big data analysis and its need for effective E-governance, International Journal of Innovations \& Advancement in Computer Science, Volume 4, Special Issue.

Bertot, J. \& Choi, H. (2013). Big Data and e-Government: Issues, Policies, and Recommendations. The Proceedings of the 14th Annual International Conference on Digital Government Research.

Chen, H., Chiang, R. \& Storey, V. (2012)." Business Intelligence and Analytics: From Big Data to Big Impact". Management Information Systems Quarterly, Vol. 36.

Gronlund, A. \& Horan, T. (2005). "Introducing e-gov: History, definitions and issues". Communications of the Association for Information Systems, Vol. 15.

Heeks, R. \& Bailur, S. (2007). "Analyzing e-government research: Perspectives, philosophies, theories, methods, and practice". Government Information Quarterly 24.

Irani, Z., Love, P., \& Montazemi, A. (2006). "Call for papers: Special issue on e-government: Past, present and future". European Journal of Information Systems.

Jeong, K. \& Kim, H. (2003). "After the introduction of the government portal services: Evolution into the mgovernment initiatives". In Proceedings of the ICA 37th Conference.

Kim, G., Trimi, S., \& Chung, J. (2014). Big-data applications in the government sector, Communications of the ACM, Volume 57 Issue 3.

Kushchu, I. \& Kuscu, H. (2003). “From E-government to M-government: Facing the Inevitable.” The 3rd European Conference on e-Government. 
Lee S., Tang X., \& Trimi S. (2005). “Current practices of leading e-government countries”. Communications of the ACM, Vol. 48, No. 10.

Manyika, J., Chui, M., Brown, B, Bughin, J., Dobbs, R., Roxburgh, C., \& Byers, A. (2011). “Big data: The next frontier for innovation, competition, and productivity", McKinsey Global Institute.

Morris, D. F. \& Moon, M. J. (2005). “Advancing E-Government at the grassroots: Tortoise or hare?" Public Administration Review, 65(1), 64-75.

Mulgan, R. (2000). “Accountability: An ever-expanding concept?" Public Administration, 78(3), 55-73.

Northrup, T. A. \& Thorson, S. J. (2003). "The Web of governance and democratic accountability." Proceedings of the 36th Annual Hawaii International Conference on System Sciences.

Premkumar, G., Ho, A., \& Chakraborty, P. (2006). "E-government evolution: an evaluation of local online services". International Journal of Electronic Business, Vol. 4, No. 2.

Reddick, C. (2005). “Citizen interaction with e-government: From the streets to servers?". Government Information Quaterly 22.

Relyea, H. C. \& Hogue, H. B. (2004). A brief history of the emergence of digital government in the United, In A. Pavlichev \& G. D. Garson (Eds.), Digital government: Principles and best practices (pp. 16-33), Hershey, PA: Idea Group Publishing.

Seifert, J. W. \& Relyea, H. C. (2004). Considering e-government from the federal perspective: An evolving concept, a developing practice. Journal of E-Government, 1(1): 7-15.

Seifter, J. \& Chung, J. (2008). “Using e-Government to Reinforce Government-Citizen Relationships”. Social Science Computer Reviews.

SMG (Seoul Metropolitan Government). (2017). Our Village Store Business Analysis Service.

Tian, J. \& Tianfield, H. (2003). “Some Perspectives of e-Government. In F. Bannister, \& D. Remenyi (Eds.) 3rd Euripean conference on e-Government.

Trimi, S. \& Sheng, H. (2008). “Emerging Trends in m-government”. Communications of the ACM, Vol 51, No. 5. 